\title{
EFFECT OF DIFFERENT MATING STIMULI ON INDUCTION OF OVULATION IN THE ALPACA
}

\author{
S. FERNANDEZ-BAGA*, D. H. L. MADDEN AND C. NOVOA \\ VITAR, Faculty of Veterinary Medicine, San Marcos University, Lima, Peru
}

(Received 30th May 1969, revised 3rd October 1969)

\begin{abstract}
Summary. The ovulation response following different mating stimuli was studied in 177 adult female alpacas killed $72 \mathrm{hr}$ after mating. Ovulation rates in females that received a mounting stimulus alone, either by aproned males or other females, were low and did not significantly differ from those controls which did not receive any stimulus. Single services by intact, or vasectomized males caused ovulation in 77 to $82 \%$ of the females, a significant increase over the previous treatments. Increasing the number of services by intact males to three within $24 \mathrm{hr}$, or interrupting services $5 \mathrm{~min}$ after their initiation, did not significantly affect ovulation or fertilization rates, as compared to single or uninterrupted services. Single HGG injections to females in oestrus induced ovulation in all cases. Results indicate that mounting accompanied by penile intromission is necessary to provide an adequate stimulus for LH release and subsequent ovulation in the alpaca.
\end{abstract}

\section{INTRODUCTION}

There appears to be some controversy as to the reproductive pattern of the members of the Camelidae family. The Bactrian camel (Camelus bactrianus L.) is described as polyoestrous, having cycles all the year round with the usual interval between heats varying from 10 to 20 days and the duration of heat from 1 to 7 days (Asdell, 1964). Shalash \& Nawito (1964), on the other hand, observed, in material collected from a slaughterhouse, that corpora lutea (CL) in the one-humped camel ( $C$. dromedarius L.) were present only in pregnant females and those with a patent os uteri, and suggested that ovulation in this species probably depends on some afferent stimulus such as copulation.

In the alpaca (Lama pacos), San-Martin, Gopaira, Zuñiga, Rodreguez, Bustinza \& Acosta (1968) reported that ovulation does not occur spontaneously; it can be induced either by copulation or by human chorionic gonadotrophin (HCG) injection, and occurs 26 and $24 \mathrm{hr}$ after copulation or injection, respectively. Furthermore, these authors stated that sterile mating is followed by pseudopregnancy, a condition observed in a considerable part of the female population, that may last for the entire breeding season in some animals. With the purpose of gaining more information about the biology of reproduction in

* Present address: Department of Animal Science, Cornell University, Ithaca, New York 14850. 
the alpaca, a series of studies was carried out at the Auchenidae Station at $\mathrm{La}$ Raya, Cusco, Peru, at an altitude of $4300 \mathrm{~m}$ above sea level during the alpaca breeding seasons of 1966 and 1967. The study reported herein deals with the relationship between the kind of stimulus and the incidence of ovulation in the alpaca.

\section{MATERIALS AND METHODS}

\section{Animals}

Adult female alpacas of the Suri and Huacaya types, ranging in age from 3 to 10 years, were used. All were bred at La Raya Experimental Station. The majority had previously produced at least one young and was culled from the breeding stock for reasons other than reproductive problems. A few of them, however, had been culled for failure to reproduce for 2 consecutive years. The males belonged to the breeding stock of the farm. All entire males were tested for their ability to produce live spermatozoa. The vasectomized males were subjected to the operation at least 36 days before their use. The operation was performed through a midline incision about $4 \mathrm{~cm}$ long in the lower end of the scrotum; bilateral segments of the vasa deferentia, about $2 \mathrm{~cm}$ long, were resected before applying a ligature to both cut ends. The sixty males used were maintained separate from the female flocks.

\section{Detection of oestrus}

Each day at about 06.30 hours and occasionally at 12.00 and 17.00 hours, two males were admitted to the corralled females. The oestrous condition of the females was detected by their characteristic behaviour; they either adopted the prone position when approached by the male, or they sought out copulating males and took a prone position nearby.

\section{Semen collection}

Semen was collected in most cases by means of electro-ejaculation, as described by Fernandez-Baca \& Calderon (1966). In a few cases, however, semen was harvested, after castration, by flushing the epididymis with heat-treated milk. Vasectomized males were also subjected to electro-ejaculation, beginning about 7 days after the operation. In the majority, spermatozoa were found in the ejaculate up to 30 days after surgery; however, no motility could be observed in most cases after 20 days.

\section{Artificial insemination}

One to $2 \mathrm{ml}$ of semen was injected into the uterus by means of a disposable plastic pipette, such as is used for bovine insemination. Raw, freshly collected semen was used in most cases, except when collected by flushing the epididymis. In females mounted by aproned males (Group 3), insemination was performed approximately $5 \mathrm{~min}$ after the insertion of a rubber catheter into the vagina. The catheter was intended to provide an additional stimulus; it was $42 \mathrm{~cm}$ long and $0.9 \mathrm{~cm}$ outside diameter and was stiffened by inserting a disposable plastic pipette into its lumen. 
Females in other groups were inseminated either immediately after termination of coitus and while they were still in the prone position (Group 6) or while being held in a standing position (Group 10). In the latter, tactile stimulation of the clitoris served to keep them quiet.

\section{Duration of copulation}

Copulation lengths were recorded to the nearest minute for intact and vasectomized males. The time from the moment the female lay down until the male rose was taken as the copulation time.

\section{Treatments}

Females showing behavioural oestrus in the presence of males were randomly allocated to one of the following treatments:

1. Controls (unmated females in heat).

2. Mounted with no penile intromission. (Seven females were mounted by other females for 10 to $16 \mathrm{~min}$ and six were mounted by aproned males for 15 to $40 \mathrm{~min}$ ).

3. Mounted by aproned males followed by artificial insemination.

4. Interrupted service. Natural service by an entire male was interrupted about 5 min after onset.

5. Sterile service. Natural service by vasectomized males.

6. Sterile service followed by artificial insemination.

7. Single service by entire males.

8. Multiple services by entire males. Each female received three services by the same male within $24 \mathrm{hr}$.

9. HCG injections; 750 i.u. HCG (Pregnyl, Organon) given as a single intramuscular injection.

10. Same as 9 but followed by artificial insemination.

After treatment, all females were removed to a separate paddock where they remained until they were killed 3 days later.

\section{Necropsy procedures}

Whole reproductive organs were removed at autopsy. Occurrence of ovulation was determined by direct inspection of the ovaries and when corpora lutea were found, the corresponding oviducts were flushed with physiological saline by means of a syringe connected to a blunt 20 -gauge needle. Washings were collected in a watch glass and examined under a dissecting microscope and cleavage states of the ova recovered were recorded. Statistical analyses of the data were carried out using $\chi^{2}$ tests, or analyses of variance.

\section{RESULTS}

Incidence of ovulation

A summary of the data on incidence of ovulation in response to the stimuli imposed is presented in Table 1. Only one animal in the unmated control group ovulated within 3 days after she was detected in heat, but no ova were recovered from the oviducts of this animal. Ovaries of the remaining nineteen animals 
contained at least one large follicle, ranging in diameter from 7.5 to $28 \mathrm{~mm}$, and having an average diameter of $11.8 \mathrm{~mm} \pm 1.8 \mathrm{~S}$.E. None of the seven females in Group 2 mounted by other females was sufficiently stimulated to ovulate, but two of the six females ovulated when mounted by aproned males. Additional vaginal stimulation followed by artificial insemination in Group 3, significantly increased the ovulation rate as compared to Group $1\left(\chi^{2}=4 \cdot 14, P<0.05\right)$. However, when the combined data of Groups 2 and 3 are compared with Group 1, the differences in ovulation rate are not significant $\left(\chi^{2}=2 \cdot 69\right.$, $P>0 \cdot 10)$. All animals in Groups 2 and 3 that failed to ovulate had large follicles, similar to the ones observed in the control group.

TABLE 1

THE NUMBER OF OESTROUS FEMALES RESPONDING TO VARIOUS KINDS OF MATING STIMULI

\begin{tabular}{l|c|c|c|c|c}
\hline \multicolumn{1}{c|}{ Nature of stimulus } & No./group & $\begin{array}{c}\text { No. } \\
\text { ovulating }\end{array}$ & $\begin{array}{c}\% \\
\text { Ovulating }\end{array}$ & $\begin{array}{c}\text { No. with } \\
\text { dividing } \\
\text { ova }\end{array}$ & $\begin{array}{c}\text { No. with } \\
\text { multiple } \\
\text { ovulations }\end{array}$ \\
\hline 1. Unmated & 20 & 1 & 5 & 0 & 0 \\
2. Mounted only & 13 & 2 & 15 & 0 & 0 \\
3. Mounted only+AI & 9 & 3 & 33 & 2 & 0 \\
4. Interrupted service & 10 & 6 & 60 & 4 & 1 \\
5. Sterile service & 22 & 17 & 77 & 0 & 2 \\
6. Sterile service+AI & 21 & 18 & 86 & $3^{*}$ & 1 \\
7. Single service & 44 & 36 & 82 & 30 & 3 \\
8. Multiple services & 10 & 7 & 70 & $6 \dagger$ & 0 \\
9. 750 i.u. HCG & 10 & 10 & 100 & 0 & 1 \\
10.750 i.u. HCG + AI & 18 & 18 & 100 & 4 & 4 \\
\hline
\end{tabular}

* Ova from three animals not recovered.

$\dagger$ Ovum from one animal not recovered.

Gopulation stimulus provided by either intact or vasectomized males (Groups 4 to 8 ), significantly increased the ovulation rate over that observed in Groups 1,2 and 3 combined $\left(\chi^{2}=52 \cdot 19, P<0 \cdot 005\right)$. Despite the short duration of the interrupted matings, the incidence of ovulations in Group 4 was not significantly different from that observed in females that received uninterrupted single services by intact $\left(\chi^{2}=2 \cdot 25, P>0 \cdot 10\right)$ or vasectomized males $\left(\chi^{2}=1.03\right.$, $P>0 \cdot 25)$. The length of forty-four uninterrupted services by entire males was $21.9 \mathrm{~min} \pm 1.2$ (mean \pm S.E.). There was no apparent relationship between copulation length and ovulation; in some cases, services lasting 10 min or less resulted in ovulation, whereas in others, services for more than 20 min failed to induce ovulation. About 20 to $30 \%$ of the females failed to ovulate in response to service by intact or vasectomized males. The ovulation response following HCG treatment (Groups 9 and 10) was significantly higher than that observed in Groups 1,2 and 3 combined $\left(\chi^{2}=49.4, P<0.005\right)$, and Groups 4 to 8 $\left(\chi^{2}=7 \cdot 31, P<0.01\right)$. In general, no significant effect of insemination on the incidence of ovulation was observed.

\section{Multiple ovulations}

The incidence of multiple ovulations was about $10 \%$ following natural service and with HCG injection, it was almost doubled (Table 1). Of the twelve 
animals showing multiple ovulation, eleven produced two ova and one produced three dividing ova (4-, 8- and 32-cell stages). In most cases, where double ovulations occurred, the eggs showed different stages of segmentation.

\section{Fertilization rates and ovarian activity}

A total of 131 ovulation points was identified in the 118 females that ovulated. From these, 121 eggs $(92.4 \%)$ were recovered by flushing the oviducts. Fiftythree of the eggs recovered were dividing and sixty-eight were not. Of the dividing eggs, seven $(13.2 \%)$ showed two cells, twenty-four $(45 \cdot 3 \%)$ four cells, twenty $(37.7 \%)$ eight cells and only two $(3.8 \%)$ more than eight cells.

Fertility rates among females mated to intact males (Groups 4, 7 and 8, Table 1), as judged by the presence of at least one dividing egg, were similar, regardless of the length or number of services. The figure of $66.6 \%$ for the interrupted service group (four females with dividing ova out of six that ovulated), was not significantly different $\left(\chi^{2}=0.93, P>0.25\right)$ from the $85.7 \%$ for Group 8.

Ovarian activity, as judged by the number of cL present on each ovary, was similar for each side. Sixty-five of the total of 131 ovulation points $(49 \cdot 6 \%)$ were located on the left ovaries and sixty-six $(50.4 \%)$ on the right ovaries. This observation differs from that of San-Martin et al. (1968) who reported more frequent ovulation of the left ovary, although their differences were not statistically significant. Mature follicles were similarly distributed in both ovaries in those animals in which ovulations did not occur. Of fifty-nine such females, thirty-two had at least one large follicle (more than $7 \mathrm{~mm}$ in diameter) on the left ovary, twenty-three on the right and two on both ovaries. In two females, both ovaries showed only small follicles less than $3 \mathrm{~mm}$ in diameter. Yet both showed behavioural oestrus.

Analysis of the data of females of Groups 7 and 8 mated to intact males shows that even though the activity of both ovaries in terms of total number of ovulations was similar, the fertilization rate of ova coming from the right and left ovaries was somewhat different. All twenty-one ova recovered from the left ovary were dividing and presumably fertilized, whereas only $81 \%$ of ova (seventeen out of twenty-one) recovered from the right side were dividing. Ghi square analysis, based on recovered ova only, showed a significant difference between both ovaries $\left(\chi^{2}=4.4, P<0.05\right)$, though the fact that more of the ova originating from the left ovary were lost (four from left: one from right) and the possibility that some of them might also have been non-dividing should be considered in evaluating this result.

\section{Diameter of corpora lutea}

The diameters of ninety CL associated with dividing, non-dividing and unrecovered eggs from both ovaries were recorded 3 days after service or gonadotrophin injection. Since ovulation has been reported to occur about $26 \mathrm{hr}$ after service or $24 \mathrm{hr}$ after HCG injection (San-Martin et al., 1968), the age of the CL must have been about $48 \mathrm{hr}$. Usually, the average of two diameters measured at right angles was taken. The average diameters and their standard errors for CL associated with dividing ova were $7 \cdot 72 \pm 0.42$ and $8.67 \pm 0.54 \mathrm{~mm}$ for the left 
and right-sided locations, respectively. The corresponding values for CL associated with non-dividing ova were $7 \cdot 46 \pm 0.38$ and $7 \cdot 76 \pm 0.32$, and those for unrecovered ova were $8.43 \pm 0.41$ and $8.23 \pm 0.43 \mathrm{~mm}$. Analysis of variance of the data revealed no significant differences in the diameters of CL associated with the status of the eggs or the side from which they originated $(P>0 \cdot 25)$.

\section{DISCUSSION}

The results of this study are in general agreement with those reported previously (San-Martin et al., 1968) in that they show the alpaca to be an induced ovulator, very much like the rabbit, mink and other animals. Occasionally, however, the alpaca seems to be capable of ovulating spontaneously, or at least without the mounting stimulus. Such ovulations may not be truly spontaneous since in these experiments, the females were not completely deprived of visual, auditory and olfactory stimuli, which may have an influence. Our results show that mounting accompanied by penile intromission appears to be necessary to provide afferent impulses adequate for the release of $\mathrm{LH}$ and subsequent ovulation. This view is supported by the observation that the response of the females to mounting without penile intromission was not significantly different from that of the control group. Mounting by other females, a treatment that simulated behaviour frequently observed among females in heat, especially in the presence of copulating males, apparently did not provide sufficient stimulus to induce ovulation.

Even though copulation takes a relatively long time in the alpaca (range: 10 to $50 \mathrm{~min}$ in our observations), there appears to be no relationship between copulation time and induction of ovulation. Females in which service was interrupted about $5 \mathrm{~min}$ after its initiation showed a similar incidence of ovulation to those that received one or three uninterrupted services. The fact that four of six ova retrieved from the interrupted-service females were dividing indicates that ejaculation occurred in spite of the short copulation time. If such is the case, one wonders what may be the physiological advantages of the long copulation time characteristic of this species.

A 20 to $30 \%$ failure in ovulation induction occurred in all cases in which females received single or multiple undisturbed services by intact or vasectomized males. Since all but two of the females that failed to ovulate showed active ovaries, as evidenced by the presence of at least one large follicle, and since ovulation always occurred after HCG injection, the main factor involved in ovulation failure appears to be LH release. It is not clear, however, whether this failure was due to inadequate stimuli, lack of response of the central nervous system to the stimuli, failure of pituitary synthesis or release of $\mathrm{LH}$, or simply to a lowered sensitivity of the follicles to the levels of $L H$ released. It is not known whether a dose of 750 i.u. of HCG is within physiological limits.

If ovulation failure occurs as frequently under practical farming conditions as in these observations, it is very likely that it may be an important contributing factor to the low fertility rates observed. Every year, about 40 to $50 \%$ of the females of breeding age fail to produce young on most commercial alpaca farms. 
The multiple ovulation rate of about $10 \%$ observed after natural matings contrasts markedly with the absence of multiple births in the alpaca, a situation that suggests the occurrence of embryonic mortality. It is not known whether one or both embryos die in those cases where double ovulation is followed by fertilization.

\section{ACKNOWLEDGMENTS}

The suggestions of $\mathrm{Dr} \mathrm{W}$. Hansel during the preparation of this manuscript are gratefully acknowledged. Facilities for the conduct of the work were provided by the Universidad Tecnica del Altiplano, Puno, at La Raya Auchenidae Station.

\section{REFERENCES}

Asdezl, S. A. (1964) Patterns of mammalian reproduction, 2nd edn, p. 556. Cornell University Press, Ithaca, New York.

Frrnandez-Baca, S. \& Calderon, W. (1966) Metodos de coleccion de semen de la alpaca. Revta Fac. Med. vet. Univ. nac., Lima, 18-20, 13.

San-Martin, M., Copaira, M., Zuñiga, J., Rodreguez, R., Bustinza, G. \& Acosta, L. (1968) Aspects of reproduction in the alpaca. 7. Reprod. Fert. 16, 395.

Shalash, M. R. \& Nawrro, M. (1964) Some reproductive aspects in the female camel. Proc. Vth Int. Congr. Anim. Reprod. Art. Insem., Trento, 1-2, 263. 